\title{
La División de Poderes en la Constitución de 1982
}

\author{
Rigoberto Armando Ramos \\ Profesor Investigador. Máster en Ciencia Política. \\ Universidad Nacional Autónoma de Honduras
}

\section{RESUMEN}

La División de Poderes es el principio político según el cual las funciones legislativa, judicial y ejecutiva del Estado deben estar separadas, como poderes independientes, para que pueda establecerse un sistema de controles y equilibrios que limite las facultades del gobierno y proteja los derechos individuales.- Principio establecido en nuestra Constitución de la República el cual no se respeta en su totalidad.

\section{ABSTRACT}

The Division of power is the political principle according to which the legislative, judicial and executive branches of the State should be separated as independent powers, so it can be a system of control and balance to limit the powers of government and to protect individual rights. - The principle established in our Constitution is not fully respected.
Palabras clave: Separación o División de Poderes.- Constitución.- Controles.Equilibrio.- Derechos individuales.
Keywords: Separation or division of powers. - Constitution. - Controls. Balance. - Individual rights. 


\section{INTRODUCCIÓN}

El presente trabajo de investigación documental se realizó basándonos en las expectativas que se vive en la actualidad en nuestro sistema democrático, por cuanto han existido hasta la fecha acciones por parte de los Poderes del Estado que ponen en precario la teoría de la división de poderes, nuestro tema "La División de Poderes en la Constitución de la República de 1982"; es un tema de suma importancia en nuestro sistema político, ya que constantemente y en el estado presente, existen situaciones de interferencia de los poderes entre sí.- Recordemos que después de la decadencia de la cultura griega y romana y durante la edad media, el monarca absoluto concentró en su persona todo el poder de su reino, o de su feudo, teniendo para sí el ejercicio de las funciones legislativas, ejecutivas y jurisdiccionales, resultando como consecuencia un poder absoluto ejercido en forma arbitrario. Para abordar el tema, he dividido el contenido en varios apartados de acuerdo al método de la investigación científica.

En primer lugar trataré la materia desde un marco teórico, en donde expongo los antecedentes de la división de poderes, desde Locke con su "Ensayo sobre el Gobierno Civil", pasando por Montesquieu, Rosseau, los Federalistas, conociendo lo que al efecto establece la Declaración de Derechos del Estado de Virginia, la Constitución de los Estados Unidos de América, la Declaración de los Derechos del Hombre y del Ciudadano y lo que declara la Constitución Francesa de 1791; sin olvidar que el Estado de Honduras tiene su origen constitucional en la Constitución de Bayona, del 6 de julio de 1808, impuesta por José Bonaparte a los españoles, en la ocupación de la Península Ibérica; y la de Cádiz de 1812, hasta llegar a la concepción contemporánea de lo que significa la división de poderes; luego analizaremos los conceptos o definiciones de lo que comprende el tema, para luego establecer lo que nuestra Constitución señala al efecto.- En este acápite de suma importancia, recojo las opiniones vertidas sobre el tema por el Doctor Efraín Moncada Silva.

En un siguiente acápite presento lo que dos analistas políticos nacionales piensan sobre el problema suscitado por la pretendida intervención de los Poderes, e incorporo una noticia de la reacción del Congreso Nacional sobre lo acontecido; seguidamente expongo mis apreciaciones sobre la realidad nacional. Para finalizar el Trabajo de la investigación expongo las conclusiones pertinentes, agregando la bibliografía consultada. El tipo de investigación que he realizado es 
explicativa en donde detallo todo lo referente a lo que significa la división de poderes tanto a nivel teórico como lo establecido constitucionalmente, y la opinión de tratadistas, concretándose también como una investigación formallegal. Presento como objetivo básico el de obtener un conocimiento científico, sobre lo que comprende la división de poderes, y como objetivos secundarios el de conocer nuestra realidad legal y social.

Puedo plantear una hipótesis general la que se concreta en declarar que en nuestro país la división de poderes no se respeta en su totalidad, aun cuando exista el equilibrio de los pesos y contra pesos, ya que se evidencian acciones por parte de los poderes del Estado que van más allá del verdadero respeto a esta división.- Es necesario aclarar de que la comparación en cuanto al respeto a la división de poderes la estoy efectuando en el tiempo actual 2009.

\section{CAPÍTULO I}

\section{ANTECEDENTE HISTÓRICO DE LA DIVISIÓN DE PODERES}

A.- No podemos referirnos a la división de poderes en la actualidad sin antes conocer su antecedente histórico y nos referimos en primer lugar a lo manifestado por el inglés John Locke, en su "Ensayo Sobre el Gobierno Civil" (1690) y específicamente en su Capítulo XII (Del poder legislativo, del poder ejecutivo, del poder federativo de la comunidad política); se refiere Locke a que el poder legislativo es el que posee el derecho a determinar cómo debe utilizarse la fuerza de la sociedad política y de los integrantes de la misma, no es imprescindible de que el órgano legislativo se mantenga en ejercicio continuamente, las leyes si son cumplidas en forma continua poseen vigencia permanente; señala Locke que no es aconsejable delegar la función de ejecutar las leyes a las mismas personas que poseen las tareas de realizarlas, puesto de que el género humano tiene la tendencia de aferrarse al poder.

Continua agregando el autor de que como las leyes se elaboran de una vez, es preciso aplicarlas ininterrumpidamente y de forma permanente, por tanto es necesario que haya un poder siempre en ejercicio que se encargue de 
la ejecución de las mismas mientras estén vigentes, de allí surge en que con frecuencia se encuentren separados los poderes legislativos y ejecutivos. En cuanto al poder federativo declara Locke Ileva consigo la capacidad de hacer la guerra o la paz, así como también la capacidad de realizar alianzas con los agentes hóstiles exteriores según sea lo más conveniente, en otras palabras lleva consigo a cuesta la política exterior; por este motivo las controversias que se originen entre cualquier componente de la sociedad y otro individuo, pertenecen a la comunidad entera, el perjuicio ocasionado al componente de ese cuerpo compromete a toda la comunidad en reclamar indemnización. Claramente establece Locke la necesidad de dividir los poderes, previendo el abuso al poder por parte de la persona humana.

B.- En su libro XI "De las Leyes que dan Origen a la Libertad Política en su Relación con la Constitución" en la obra "El Espíritu de las Leyes"(1748) el francés Charles Louis de Secondat, Barón de Montesquieu, desarrolla las ideas de John Locke sobre la división de poderes y nos ilustra al respecto señalando de que la libertad política solo se encuentra en los Estados moderados y solo aparece cuando no se abusa del poder.- Pero es una experiencia eterna que todo hombre que tiene poder siente la inclinación de abusar de él, yendo hasta donde encuentra límites "iquién lo diría! La misma virtud necesita límites". Para que no se pueda abusar del poder es preciso que, por disposición de las cosas, el poder frene al poder.- Una constitución puede ser tal que nadie esté obligado hacer las cosas no preceptuadas por la ley, y a no hacer las permitidas, agrega Montesquieu.

Hasta aquí Montesquieu nos declara la necesidad del equilibrio entre poderes, pero la esencia de la división lo establece cuando dice que hay en cada Estado tres clases de poderes: el poder legislativo, el príncipe y el magistrado que promulga leyes para cierto tiempo o para siempre, y enmienda o deroga las existentes.- Pero el segundo poder dispone de la guerra o de la paz, envía o recibe embajadores, establece la seguridad, previene las invasiones.- El tercero castiga los delitos o juzga las diferencias entre particulares. Llamaremos a éste Poder Judicial, y al otro Poder Ejecutivo del Estado. Cuando el poder legislativo está unido al poder ejecutivo, en la misma persona o en el mismo cuerpo, no hay libertad porque se puede temer que el monarca o el senado promulguen leyes tiránicas para hacerlas cumplir tiránicamente. Tampoco hay libertad si el poder judicial no está separado del 
legislativo ni del ejecutivo.- Si va unido al poder legislativo, el poder sobre la vida y la libertad de los ciudadanos seria arbitrario, pues el juez seria al mismo tiempo legislador.- Si va unido al poder ejecutivo, el juez podría tener la fuerza de un opresor.

Agrega Montesquieu de que todo estaría perdido si el mismo hombre, el mismo cuerpo de personas, de los nobles o del pueblo, ejerciera los tres poderes: el de hacer las leyes, el de ejecutar las resoluciones públicas y el de juzgar los delitos o las diferencias entre particulares. (Montesquieu, 1748).

C.- Juan Jacobo Rousseau en su obra "El Contrato Social" (1762) hace referencia a la división de poderes al señalar de que una vez de que se halle establecido el poder legislativo, se trata de instituir del mismo modo el poder ejecutivo, este último que no obra sino por actos de naturaleza particular, debe de estar separado del poder legislativo, si el soberano tuviera ambos poderes el derecho y el hecho quedarían confundidos y no se podría saber lo que era una ley y lo que no era. (Rousseau, 1762).

D.- Hemos tomado del Libro "El Federalista" lo que se entiende por separación de poderes: "Los Departamentos Legislativo, Ejecutivo y Judicial deben ser distintos y diferentes". "Ninguna verdad política es ciertamente de mayor valor intrínseco, ni está autorizada por tan ilustres defensores de la libertad...La acumulación de todos los poderes, legislativos, ejecutivos y judiciales, en las mismas manos, sean éstas de uno, de pocos o de muchos, hereditarias, autonombradas o electivas, puede decirse con exactitud que constituye la definición misma de la tiranía." (Madison, 1787-1788) ${ }^{1}$. Madison cita un pasaje de Jefferson tomado de sus notas sobre el Estado de Virginia.- El gobierno por el que lucharon, según Jefferson, es "uno que no solamente se funde en principios libres, sino que sus poderes estuvieran divididos y equilibrados de tal modo entre distintos cuerpos de magistrados, que ninguno pasara de sus límites legales sin ser contenido y reprimido eficazmente por los otros".

Constituye lo que Jefferson señala el equilibrio de poderes o los pesos y contrapesos que deben de existir entre los poderes a fin de garantizar su inde-

\footnotetext{
${ }^{1}$ El Federalista es la defensa pública a la Constitución de los Estados Unidos, aparecida en forma de 85 cartas firmadas por el seudonimo "Publius". Sus autores son en realidad Alexander Hamilton, John Jay y James Madison
} 
pendencia y participación en el gobierno del Estado. Los federalistas tomaron de base para sus escritos relativos a la división de poderes, lo expresado por Montesquieu respecto a la Constitución británica.

E.- En atención a la materia estudiada, Derecho Constitucional, incorporamos a continuación documentos que afianzan los conocimientos sobre la división de poderes, en la "Declaración de Derechos de Virginia" del 12 de junio de 1776 señala: "V.- Que los poderes legislativo y ejecutivo del Estado deben estar separados y diferenciados del judicial y que para impedir que los miembros de los dos primeros incurran en opresión, han de sentir las cargas del pueblo y participar de ellas, recuperando cada cierto tiempo su condición privada al volver al cuerpo del que procedían, supliendo las vacantes mediante elecciones frecuentes y regulares en las que, todos o partes de los antiguos miembros, podrán ser de nuevo elegibles o inelegibles, según lo que establezcan las leyes."(www.der.uva.es).

F.- La Constitución de los Estados Unidos de América del 17 de septiembre de 1787, establece en cada uno de sus primeros tres Artículos la división de poderes, al establecer en cada uno, cada poder, el Artículo uno, trata sobre el poder legislativo y declara que todos los poderes legislativos otorgados por esa Constitución, corresponderán a un Congreso de los Estados Unidos, que se compondrá de un Senado y de una Cámara de Representantes. Desarrollado este artículo en diez secciones. El Artículo dos, se refiere al poder ejecutivo cuando dice que se deposita el poder ejecutivo en un Presidente de los Estados Unidos el que desempeñará su cargo por cuatro años, junto con un Vicepresidente, agregando a continuación la forma de elección, conteniendo cuatro secciones. Y el Artículo tres, que declara de que se depositará el poder judicial de los Estados Unidos en un Tribunal Supremo y en los tribunales inferiores que el Congreso instituya y establezca en lo sucesivo; asimismo, existen tres secciones en donde se desarrolla todo el contenido del Artículo tres.(http://usinfo.state.gov/). Como se puede observar la Constitución de los Estados Unidos de América desde su inicio establece la división de poderes.

G.- Como producto de la Revolución Francesa se emite la Declaración de los Derechos del Hombre y del Ciudadano el 26 de agosto de 1789, en su Artículo 16 la Declaración señala: "Toda sociedad en la cual no esté 
establecida la garantía de los derechos, ni determinada la separación de los poderes, carece de Constitución". (www.elysee.fr/esp).

H.- La Constitución Francesa del 3 de septiembre de 1791 declara en su Título III De Los Poderes Públicos, Artículo 12.- "La Nación, de quien emanan todos los poderes, no puede ejercerlos más que por delegación.- La Constitución Francesa es representativa: Los representantes son el Cuerpo Legislativo y el Rey". Artículo 13.- El Poder Legislativo se delega en una Asamblea Nacional compuesta por representantes temporales, libremente elegidos por el pueblo, para que sea ejercido por ella, con la sanción del Rey, de la manera en que se determinará a continuación. Artículo 14.- El gobierno es monárquico: el Poder Ejecutivo se delega en el Rey, para que sea ejercido bajo su autoridad por ministros y otros agentes responsables, de la manera en que se determinará a continuación. Artículo 15.- El poder judicial se delega en jueces elegidos periódicamente por el pueblo". (www.der.uva.es).

I.- La Constitución Política de la Monarquía Española, sancionada el 19 de marzo de 1812, señala en su Título II, capitulo III, lo que se relaciona con el gobierno y establecen sus Artículos lo siguiente: Artículo 13.- El objeto del Gobierno es la felicidad de la Nación, puesto que el fin de toda sociedad política no es otro que el bienestar de los individuos que la componen. Artículo 14.- El Gobierno de la Nación Española es una Monarquía moderada hereditaria. Artículo 15.La potestad de hacer las leyes reside en las Cortes, con el Rey. Artículo 16.- La potestad de hacer ejecutar las leyes reside en el Rey. Artículo 17.- La potestad de aplicar las leyes en causas civiles y criminales reside en los tribunales establecidos por la ley. (www.der.uva.es). Como se puede observar al plasmar el contenido de cada Constitución, el principio de la división de poderes ha quedado establecido como un paradigma para futuras cartas magnas, situación que se ha evidenciando, en nuestro caso, desde la primera Constitución Federal y la primera Constitución Estatal.

\section{CAPÍTULO II}

\section{CONCEPTOS DE DIVISIÓN DE PODERES}

De acuerdo al antecedente histórico, el concepto más simple que se colige es que la división de poderes es la forma de evitar que una persona tenga en sus manos 
todos los poderes del Estado, a fín de garantizar a la persona humana el respeto de sus derechos individuales, aunque existen tratadistas del tema que opinan de diferente manera, expondremos a continuación lo referente.

A.- "La separación de poderes o división de poderes (en latín trias política) es una ordenación y distribución de las funciones del Estado, en la cual la titularidad de cada una de ellas es confiada a un órgano u organismo público distinto. Junto a la consagración Constitucional de los derechos fundamentales, es uno de los principios que caracterizan el Estado de Derecho Moderno".

B.-Separación de Poderes: Es el principio político según el cual las funciones legislativa, judicial y ejecutiva del Estado deben estar separadas, como poderes independientes, para que pueda establecerse un sistema de controles y equilibrios que limite las facultades del gobierno y proteja los derechos individuales.- El poder legislativo delibera y decide el contenido de las leyes generales : esta tarea es necesariamente más lenta que otras, porque las leyes deben estar cuidadosamente hechas para que sean reconocidas como legítimas por la mayor parte de la población y de los grupos de interés en el país.- El poder judicial aplica las leyes generales a los casos particulares y el poder ejecutivo, aparte de hacer efectivas las decisiones de los otros dos poderes, maneja la administración general del país y atiende su bienestar general. (http://www.eumed.net).

\section{CAPÍTULO III}

\section{CONSTITUCIÓN POLÍTICA DE HONDURAS DE 1982}

Siguiendo con la doctrina de la separación de poderes establecidos en las Constituciones de los Estados Unidos de América de 1787 y la de Cádiz de 1812, Honduras desde la Constitución Federal de 1824 y la primera estatal de 1825, adoptaron la doctrina de separación de poderes.

Para Analizar la Constitución vigente, emitida mediante Decreto No. 131 del 11 de enero de 1982, nos hemos auxiliado del Capítulo XII del Libro "Temas Constitucionales" elaborado por el Doctor Efraín Moncada Silva, que trata el tema con mucha propiedad; haciendo un resumen de su contenido, incorporando descripciones y actualizando las disposiciones constitucionales. La Constitución 
de 1982, establece en su Artículo 4:- La forma de gobierno es republicana, democrática y representativa.- Se ejerce por tres poderes, Legislativo, Ejecutivo y Judicial, complementarios e independientes y sin relaciones de subordinación.

La Asamblea Nacional Constituyente, al elaborar la Constitución comentada, tomó en consideración, en primer lugar la forma de gobierno y en segundo término la teoría de la separación de poderes, ya estatuidos en las Constituciones anteriores, estableciendo además en su contenido, las atribuciones que expresamente le corresponden a cada uno de los poderes del estado y que integran la esfera de competencia de estos poderes.

A.- Las atribuciones del Poder Legislativo se encuentran establecidas, en su mayoría en el Artículo 205; las del Poder Ejecutivo en el Artículo 245 y las del Poder Judicial en los Artículos 313 y 316.- No obstante el gobierno se ejerce por medio de los tres poderes que son a su vez, complementarios e independientes sin relación de subordinación. El legislador estableció el hecho de que los poderes no solo son independientes, sino que enfatizó, además que no están sujetos a relaciones de subordinación.- "Aquí radica el verdadero equilibrio del poder público, porque cada órgano esencial del Estado está en manos de diferentes titulares, tienen su propia esfera de competencia y ninguno de ellos está subordinado a los otros," señala el Doctor Moncada Silva.

B.- En cuanto al control reciproco de los poderes del estado, con el sistema de frenos y contrapesos que aparece en la Constitución de los Estados Unidos, sin que sea lo mismo, se da en nuestra Constitución.- Existen mecanismos de control mediante los cuales los órganos esenciales del Estado, se complementan, autorizan, aprueban, fiscalizan o revisan los actos entre sí; estas facultades de control deben estar expresamente establecidas, claras y precisamente determinadas en la Constitución.

Como ejemplo de lo anteriormente señalado, el Congreso tiene la atribución de aprobar o improbar los contratos celebrados por el Poder Ejecutivo o el Poder Judicial indicado en el Artículo 205, numeral 19 del texto constitucional, igualmente existe control del Poder Legislativo acerca de las actuaciones del Poder Ejecutivo en los numerales 13, 22, 23, 27, 30, 32, 36, 41; en el numeral 20 se establece el mecanismo de control que el Congreso 
Nacional utiliza con relación al Poder Ejecutivo, Poder Judicial, Tribunal Nacional de Elecciones, Tribunal Superior de Cuentas, Procuraduría General de la República, Procuraduría del Medio Ambiente, Ministerio Público, Comisionado Nacional de los Derechos Humanos, Instituciones Descentralizadas y demás Órganos Auxiliares y Especiales del Estado; al aprobar o improbar la conducta administrativa de estos.

Por el otro lado, el derecho al veto suspensivo que tiene el Presidente de la República para rechazar un proyecto de ley, aprobado por el Congreso Nacional establecido en el Artículo 216 constitucional, es un mecanismo de control del Poder Ejecutivo sobre los actos del Poder Legislativo. La revisión constitucional de las leyes, por medio del recurso de inconstitucionalidad, previsto en los Artículos 184 y 185 de la Constitución y cuyo conocimiento originario compete a la Corte Suprema de Justicia, es un mecanismo de control del Poder Judicial sobre los actos esenciales del Congreso Nacional.

Los mecanismos de control están comprendidos dentro del concepto de complementariedad de los poderes que se halla prescrito en el Artículo 4 de la Constitución. Por medio del control recíproco se trata de lograr un equilibrio razonable de los poderes en beneficio de la actividad general del Estado, que viene a trascender en los gobernados para salvaguardar sus derechos, civiles, políticos, económicos, sociales y culturales; pudiendo accionar contra las arbitrariedades establecidas, bien en una norma general secundaria, una norma reglamentaria o bien en cualquier acto administrativo de carácter particular que lesione sus derechos subjetivos o su interés legítimo.

C.- Aclara el Doctor Moncada Silva, que con el objeto de preservar el principio de la independencia de los poderes, las disposiciones constitucionales que establecen los mecanismos de control, que en este caso constituyen una excepción al mencionado principio de separación de poderes, deben ser expresas, claras y precisas, a fin de que no suscite dudas ni ambigüedades; $y$, en el caso de que estas excepciones se presentaren, habría que interpretarlas a favor de la ausencia o del menor control de un poder sobre otro, a fin de evitar los abusos de poder. En cuanto al control o invasión de competencias, el Doctor Moncada Silva señala como corolario de la independencia de los poderes, que no existe ni debe de existir preeminencia o predominio de uno sobre los otros; los tres tienen la misma jerarquía y están en el mismo nivel.Por el hecho de que el Congreso Nacional elija a los magistrados a la Corte 
Suprema de Justicia, por mandato de la propia Constitución, no debe de inferirse que el Poder Judicial tenga menor categoría que el primero. Los mecanismos de control, algunos de los cuales son a priori y otros a posteriori, manifestados en actos de naturaleza legislativa, administrativa o jurisdiccional, no solamente deben de estar debidamente justificados, expresamente establecidos en el texto constitucional, sino también correctamente interpretados y razonablemente aplicados.

Por las razones anteriores, la atribución del Congreso Nacional de "nombrar comisiones especiales para la investigación de asuntos de interés nacional" (artículo 205, numeral 21), no debe de ser ni seguir siendo interpretada, como lo fue en algún tiempo, en el sentido de que el Congreso Nacional está autorizado para invadir las esferas de competencias constitucionales del Poder Judicial o del Poder Ejecutivo. Si el Congreso Nacional, so pretexto de estar ejerciendo la referida atribución, investiga para el caso las actuaciones y conductas de los magistrados y jueces, para determinar si existe o no corrupción o funcionamiento irregular en el Poder judicial, está invadiendo las competencias propias de otro poder del Estado y menoscabando su independencia, y en los hechos situándolo en una relación de subordinación. Para que sea el propio Poder Judicial el que ponga orden en su casa, la Constitución dispone que la Ley se encargue de regular la organización y funcionamiento de los tribunales y juzgados (Artículo 307) ${ }^{2}$. Asimismo, que los jueces y magistrados no podrán ser separados, suspendidos, trasladados, descendidos ni jubilados, sino por las causas y con las garantías previstas en la ley; y se instituye, además, la carrera judicial. Resume el tratadista comentado que la atribución 21 del Artículo 205, constitucional, autoriza al Congreso Nacional a nombrar comisiones especiales para la investigación de asuntos de interés nacional, como el cumplimiento de las disposiciones sobre los derechos humanos; las causas reales del desempleo, de la violencia y de la delincuencia en el país; la protección y seguridad de los habitantes del país; el control del presupuesto de las Fuerzas Armadas, etc. etc., pero nunca para investigar asuntos concretos que atañen al funcionamiento de los otros poderes del Estado que caen dentro de las competencias constitucionales y propias de éstos. Finaliza el capítulo el Doctor Moncada Silva declarando, de

\footnotetext{
${ }^{2}$ Artículo 307. - La ley sin menoscabo de la independencia de los jueces y magistrados, dispondrá de lo necesario a fin de asegurar el correcto y normal funcionamiento de los órganos jurisdiccionales, proveyendo los medios eficaces para atender a sus necesidades funcionales y administrativas, así como a la organización de los servicios auxiliares.
} 
que una cosa es el control recíproco de los poderes establecidos en la propia Constitución y otra diferente es que el Congreso Nacional o cualquier otro de los poderes se arrogue atribuciones, por la vía de la interpretación o aplicación injustificada de alguna, para invadir competencia de los otros. (Moncada Silva, 2001).

\section{CAPÍTULO IV}

\section{SITUACIONES POLÍTICAS EN RELACIÓN A LA DIVISIÓN DE PODERES}

En el presente capítulo expondremos las opiniones de diferentes analistas y noticias sobre los acontecimientos nacionales que tienen relación con la división de poderes, para continuar posteriormente expresando nuestro criterio sobre el tema.

Buscando en la Web nos encontramos con las siguientes opiniones:

A.- "Cooperación o Pleito entre Poderes", así titula el columnista Benjamín Santos a su escrito publicado en el Diario La Tribuna del sábado 31 de mayo del 2009, relacionado con la separación de poderes y declara: "Desde el punto de vista teórico y normativo la cosa está más clara que la luz del día cuando hace sol. Los poderes del Estado en los sistemas republicanos de tipo presidencialistas son independientes y complementarios, es decir sin relaciones de subordinación, sino de cooperación. En estos sistemas como ocurre en Honduras la separación de poderes resulta más clara que en los sistemas parlamentarios de tipo europeo, sean monárquicos o republicanos, porque los titulares del Ejecutivo y los integrantes del Legislativo surgen de la voluntad del pueblo de manera que no puede uno decretar la disolución o destitución del otro.

Diríamos que son como tres reos atados a la misma cadena, o saltan los tres al mismo tiempo para avanzar o se enredan en la cadena obstaculizándose al avance mutuamente. El principio de separación de las grandes funciones del Estado en órganos diferentes, tuvo su origen en las malas experiencias que tuvieron los pueblos al concentrar todo el poder en una sola persona, es decir como un rechazo a la monarquía absoluta. La democracia surgió en Atenas como un rechazo a la monarquía y al régimen de los 30 tiranos". 
Continúa el columnista explicando el surgimiento de la teoría de la división de poderes para llegar al meollo del asunto analizado, lo que constituye la intromisión de los titulares de los poderes del Estado en los asuntos propios de cada uno y señala:

"Conociendo el origen histórico, doctrinario y normativo de la división de poderes, no podemos menos que sorprendernos por el pleito entre los titulares de los poderes del Estado en Honduras. Se queja la Presidenta de la Corte Suprema de Justicia de la intervención del Poder Ejecutivo en el ámbito de sus atribuciones y el Ejecutivo se queja en una campaña publicitaria que la Corte no coopera para llevar a cabo las políticas que define su titular en Consejo de Ministros. En la teoría de la división de poderes desde sus remotos orígenes hasta hoy no se encuentra nada que diga que el Poder Judicial debe orientar sus decisiones a estar a favor o en contra de las decisiones del Poder Ejecutivo, porque su función es juzgar y ejecutar lo juzgado bajo un estricto apego al principio de legalidad. Tampoco se encuentra nada que justifique la existencia de una Corte-Parlamento donde estén representados los partidos políticos.

Es tolerable y hasta lógico que haya una relación dialéctica entre el Ejecutivo y el Legislativo, porque ambos son órganos políticos o políticoadministrativos, pero no en el caso que citamos anteriormente. El problema se resuelve fácil. Hay que releer la Constitución y la doctrina sobre el sistema republicano, democrático y representativo. Hay que inyectar a los miembros de los tres poderes contra el virus del sectarismo y con neurovión para que calmen sus nervios y recuperen la conciencia de que con sus actuaciones perjudican o benefician a la colectividad." (Santos, 2009).

Por su parte Rafael Delgado Elvir, columnista del Diario La Prensa en su edición del 6 de abril del 2008, se refiere en similares términos en su análisis del problema, con el título de "División de Poderes" y dice:

"La división de poderes es la garantía del gobierno republicano y el escudo contra el absolutismo; hace más de dos siglos fue enunciado y desde entonces figura en las constituciones de los países democráticos. No es un personaje el que manda, como cuando aquel déspota proclamaba "el estado soy yo", son tres poderes independientes uno del otro ejercidos por personas distintas en un esquema de mutua colaboración para garantizar el bien común. 
La división de poderes es una conquista política que marcó un rumbo distinto para la humanidad, producto de un hecho revolucionario, herencia del talento y el espíritu transformador de los ilustrados de un ayer. Cada poder tiene su esfera de competencias, tanto el Poder Ejecutivo, como el Poder Legislativo y el Poder Judicial, todos colaboran para que cada uno tenga un buen desempeño, pero ninguno, so pena de caer en el delito de la usurpación, puede invadir las funciones del otro. El caso más frecuente de invasión de facultades ajenas en estas heredades del atraso, ocurre cuando al presidente del Poder Legislativo le da por ser candidato presidencial, entonces es muy frecuente que este funcionario, desesperado por congraciarse con los electores, salte barreras prohibidas por la Constitución. Esto es grave sobre todo cuando cuantiosos fondos presupuestarios le son reservados para andar para arriba y para abajo entregando subsidios que si bien son recibidos como bendición del cielo por los beneficiarios, existe gente pobre que necesita de la atención del Estado, nadie ignora que esto corresponde al poder Ejecutivo en el marco de su política social.

No he visto en ningún país organizado este fenómeno que otorga ventajas financiadas por el Estado a alguien que debe competir con otros que no disfrutan de estos fondos ni de estas prerrogativas, por eso es que la Constitución prohíbe al Presidente de la República o al Presidente del Congreso ser candidatos a la máxima representación nacional. La lucha electoral debe ser altamente competitiva para que sea legítima, esto significa que nadie debe tener más ventajas que las que le otorga su propio talento o su raigambre popular, si alguien entra pertrechado de dineros estatales o de influencias es igual como cuando antes los candidatos militares entraban a la campaña electoral pistola en cinto y protegidos por el poder que otorgan las armas. No se me ocurre qué hacer para que esta deformación no ocurra en Honduras, de momento la única conducta apropiada que puede esperarse es el escrúpulo republicano, la pregunta es si tendrán esta altura los funcionarios pre candidatos." (Delgado, 2008).

B.- Pero el problema del irrespeto a los poderes del Estado y la intromisión por parte del Ejecutivo en el Poder Judicial se evidencia también cuando el Congreso Nacional protestó el año del 2007, por injerencias del Poder Ejecutivo en las decisiones del Poder Judicial; Diario La Prensa en su edición del 14 de diciembre de 2007 informa con el título de "Sorprendidos por 
Injerencia"; "Tegucigalpa. Los diputados del Congreso Nacional reaccionaron sorprendidos al conocer que la comisión de juristas nombrada por Casa Presidencial intentó ayer influir sobre la Corte Suprema de Justicia. Casi en coro, los legisladores calificaron la acción de los juristas como una injerencia del Poder Ejecutivo en los asuntos de la Corte Suprema de Justicia, al tiempo que advirtieron que con esta actitud "desde Casa Presidencial se está propiciando una grave crisis institucional".

A juicio del diputado Juan Orlando Hernández, "el mensaje que están dando estas personas es muy delicado y se presta a muchas interpretaciones. En primer lugar por estar poniendo en duda la capacidad de los magistrados de la Corte de resolver un asunto de su competencia y, por otro lado, se percibe que es una intromisión de poderes. Sorprende mucho la actitud de estos profesionales, pues ellos saben muy bien que mientras un tema es sometido a la consideración de la Corte, ningún otro poder del Estado debe intervenir", afirmó.

Mel incluido.- Si de deducir responsabilidades se trata, advirtió, habrá que hacerlo con el ex presidente Manuel Zelaya, que en aquella oportunidad formó parte de la comisión política del Partido Liberal que dio luz verde a la reforma. La comisión estaba integrada, además, por Jaime Rosenthal y Jorge Arturo Reina, y por el Partido Nacional estaban Jorge Ramón Hernández Alcerro, Juan Orlando Hernández y Jorge Carranza.

Pero también tendrían responsabilidad los firmantes de un pacto político que fue auspiciado por las Naciones Unidas, el que fue firmado por representantes de la sociedad civil como testigos de honor y por las dirigencias de los partidos políticos legalmente inscritos en el país. "Si la Corte decide que la reforma no estuvo bien hecha, tenemos que respetar esa decisión; pero eso no significa que incurrimos en una responsabilidad, porque no lo hicimos con el ánimo de perjudicar al país", justificó Hernández Alvarado. El diputado liberal José Azcona indicó que en torno al caso de Micheletti "se están viendo señales muy feas y da la impresión de una injerencia del Poder Ejecutivo en las decisiones de la Corte Suprema". Arnulfo Miralda señaló que "se está sintiendo como una intervención directa y ojalá no sea así". El diputado nacionalista Antonio Rivera Callejas dijo que con estas acciones "da la impresión de que nos quieren Ilevar a una crisis institucional, lo cual es muy peligroso". (Diario La 
Prensa, 2007). Es posible escribir muchas páginas sobre lo que la prensa nacional ha manifestado en varias ocasiones, en relación a la injerencia de los Poderes del Estado entre sí, pero solamente exponemos estas tres referencias para darnos cuenta de que existe un problema de irrespeto a la independencia de los poderes.

\section{CAPÍTULO V}

\section{BREVE ANÁLISIS SOBRE EL RESPETO A LA DIVISIÓN DE PODERES}

La Constitución de la República es considerada como una de las constituciones más completas y avanzadas de América Latina, ya que contiene disposiciones que protegen y garantizan el respeto a los Derechos Humanos por parte del Estado; pero no todo es como lo establece la carta magna, ya que en innumerables ocasiones sus disposiciones han sido violentadas por el gobierno, hechos que se sintieron con mayor profundidad durante la guerra fría, cuando la doctrina de la seguridad nacional prevaleció sobre los derechos y seguridad de la persona humana, y es que en esa oportunidad los poderes constituidos estaban sometidos a lo que establecían las Fuerzas Armadas, al grado de que el sometimiento era tan evidente que en los puestos de dirección y ejecución de los tres poderes del Estado eran ejercidos por recomendados de la milicia; por tanto en esa época no existían conflictos de interferencia de los poderes del Estado entre sí.

A medida que pasan los años, los poderes van adquiriendo verdadera independencia a raíz de la caída del muro de Berlín, y el surgimiento interno de grupos de la sociedad civil organizada, que promueven el respeto de los derechos humanos y el establecimiento real y efectivo de una doctrina democrática, que propugna por la participación ciudadana en la gobernabilidad del Estado. Los conflictos del irrespeto a la independencia de los poderes han surgido últimamente promovidos por dos razones a mi modo de ver: la primera se le atribuye al fervor de algunos grupos de dirigentes de los partidos políticos ( no digo políticos, porque si fueran políticos no actuarían al margen de la ley y del bienestar colectivo), que buscan alcanzar el poder aún a costa de violentar la Constitución, con la participación o contubernio de dos poderes, el otro de los cuales quiere mantenerse en el poder. La segunda razón se la atribuyo al 
desconocimiento que uno de los poderes tiene para ejecutar correctamente las acciones o políticas públicas en la administración del Estado, dando como resultado que cuando sus actos administrativos son anulados por el poder jurisdiccional, en aplicación de su legal competencia y en atención a la petición de los interesados, trata de interferir en su independencia, mediante la presión social, y administrativa a fin de obtener sentencia de acuerdo con sus pretensiones, no importando el hecho de que sus actos sean violatorios al derecho de las personas o a sus intereses legítimos.

Resulta difícil mantener incólume la independencia de los poderes del Estado mientras existan intereses políticos por parte de sus máximas autoridades o representantes legales de los mismos, no obstante que sepan que no son más que servidores del pueblo, que tienen que obedecer el mandato popular de buscar el bienestar público, ya que la persona humana es el fin supremo de la sociedad y del Estado y por tanto todos y especialmente el Estado tienen la obligación de respetarla y protegerla.

\section{CONCLUSIONES}

1.- La teoría de la división o separación de poderes, desarrollada por Montesquieu ha sido aceptada por la mayoría de los países del mundo, principalmente los occidentales y ha sido plasmada en la Constituciones de cada uno de ellos.

2.- Esta teoría tiene como fundamento en que el poder no puede estar en manos de una sola persona o de pocas personas, sino que debe de ser depositado de acuerdo a su función en tres poderes independientes pero complementarios entre sí.

3.- Honduras recoge esta teoría y la plasma en sus Constituciones, desde la Federal del 22 de noviembre de 1824, la primera Constitución nacional jurada en Comayagua el 11 de diciembre de 1825, en ambas se establece la estructura clásica de los tres poderes del liberalismo francés: Legislativo, Ejecutivo y Judicial No hay que olvidar que antes de estas Constituciones Honduras se regía por la Constitución de Cádiz del 19 de marzo de 1812, arriba señalada.

4.- La Constitución vigente, Decreto No. 131 del 11 de enero de 1982 recoge disposiciones referentes a la división de poderes en su Artículo 4, así como las atribuciones específicas de cada uno de los Poderes, Legislativo, Ejecutivo y Judicial. 
5.- No siempre se ha respetado la independencia de los poderes del Estado, estos en muchas ocasiones han sido objeto de intervenciones de otros poderes o grupos de presión, a fin de influir en las funciones propias de cada uno de ellos.

6.- En la actualidad la presión para que el Poder Judicial actúe en beneficio de los intereses de los representantes del Poder Ejecutivo y el Poder Judicial, es de todos conocida, al grado de que varios analistas políticos se han manifestado preocupados, ya que se ha puesto en peligro la estabilidad democrática del Estado.

7.- No obstante hasta la fecha ha sido posible frenar las pretensiones de los interesados en desestabilizar el sistema democrático, por la participación de la sociedad civil y la empresa privada.

\section{BIBLIOGRAFÍA}

Constitución de la República.- Decreto No. 131 del 11 de enero de 1982.

Delgado Elvir, Rafael.- "División de Poderes. "La Prensa.- 6 de abril de 2008.

El Federalista.- www.librolibre.org.ni/DocPo/edu/const/feder2.html

Enciclopédia Virtual.- Universidad de Málaga.- http://www.eumed.net

Locke, John.- "Ensayo Sobre el Gobierno Civil" (1690).- Ediciones Alba, 1987, Material sobre Derecho Constitucional, septiembre, 2000.- Universidad de Valladolid, España.- www.der.uva.es

Moncada Silva, Efraín.- "Temas Constitucionales".- Ed.Edigrafic. S de R.L. Tegucigalpa, 2001, pag 181-187.

Montesquieu, Charles Louis de Secondat.- "El Espíritu de las Leyes" (1748).-

Copyright by Tecnos, 1980.- Material de Derecho Constitucional, septiembre 2000.- Universidad de Valladolid, España.- www.der.uva.es

Presidencia de la República Francesa.- www.elysee.fr/esp

Programa de Información Internacional del Departamento de Estado de EE.UU. http://usinfo.state.gov/espanol/constes.htm

Rousseau, Juan Jacobo.- "El Contrato Social".- 1 ed: Buenos Aires.- Longseller, 2005.

Santos, Benjamín.- "Cooperación o Pleito entre Poderes." La Tribuna.- 31 de mayo de 2008.

Sorprendidos por Injerencia".- La Prensa.- 14 de diciembre de 2007. 